\title{
Study of gradation characteristicsbased on subgrade filling with weathered phyllite by cement
}

\author{
Wenjie Cen ${ }^{1, a}$ Qingmeng Meng ${ }^{2, b}$ \\ $5437848 @ q q . c o m$ mengqm66@163.com \\ CCCC Fourth Harbor Engineering Institute Co.,Ltd Guangzhou 510000
}

\begin{abstract}
Key word: Phyllite property improvement; Subgrade ; Gradation
Abstract.This article is based on the practical engineering need of expressway .Study about the mechanical properties of phyllite filler, and then improve the property by using the cement. Testing the original rock phyllite minerals analysis experiment, uniaxial compressive strength test and physical parameters of phyllite filling test and water disintegration test and analysis. After that we make test about different gradation of the cement improved phyllite packing compaction test and unconfined compressive strength test, analyzed the change characteristics of modified phyllite filler engineering, comprehensive analysis and selection of cement admixture is $3 \%$, content of coarse aggregate gradation is 55\%.This is the best combination to meet the requirements of economy and the mechanical properties.
\end{abstract}

\section{Introduction}

The geology at distribution area of phyllite are usually very complex. Considering the construction period, investment and environmental protection requirements, the use of longitudinal excavation and excavation of tunnel debris shift is the best choice.

At present, the most research on soft rock in engineering is focused on the engineering performance, feasibility, improvement of the strength and water immersion characteristics of the fillers. Considering the effect of filler on properties of phyllite roadbed is small and is not thorough with gradation factors. Mao Xuesong [1] studied Shiyan to Tianshui highway Ankang eastern section of roadbed wet deformation and modulus of resilience for field test, On the basis of weathering phyllite stuffing physical and mechanical properties analysis of subgrade filling scheme is proposed and through the field test of before and after immersion of the bearing plate test and analysis of soaking amount soaking time on wet deformation、 influence of deformation rate and resilient modulus of subgrade; and combined with different depth water content test and analysis the test rate of water content and infiltration depth and wet deformation of correlation. Zhou Leigang [2] studied strongly weathered phyllite roadbed filling technology as the research object by indoor test and field test of a combination of methods, from weathered phyllite before and after the improvement of physical and mechanical properties and road use performance and construction technique of cement modified phyllite roadbed filling technology of systematic research. Zheng Xiaozhong[3] through laboratory test, field test and numerical calculation method of weathered phyllite roadbed filling of humidification deformation characteristics were studied. Huang Chengjia [4] studied strongly weathered phyllite stuffing as the research object through laboratory and field tests and analysis the change of grading to determine the scope of reasonable gradation; also in phyllite low strength characteristics, and analyzed the level effect of paired modified phyllite stuffing mechanical properties; and also based on the road test based on the proposed phyllite roadbed filling scheme and construction technology, made a series of achievements. Mao Xuesong [5] studied the effect of moisture on the variation of the modulus of elasticity of the subgrade by the test of the water supply of the $1.2 \mathrm{~m} * 1 \mathrm{~m} * 1 \mathrm{~m}$ test tank.

\section{The analysis of the composition and mechanical properties of the original rock}

\section{Mineral composition of phyllite}

There is phyllitic structure obviously, fresh face is reddish brown, weathered face pale gray, in the case of water it turns to grayish, with poor weathering resistance and water resistance.It is 
known from X-ray diffraction experiment (Figure 1), the main mineral components of phyllite is: K0.5 1 (al, Fe, Mg) 2 (sial) $4 \mathrm{O} 10$ (OH) 2 (sericite), SiO2 (quartz), K (Mg, Fe) 3 (alsi3O10) (oh, f) 2 (biotite), (Mg, Al, Fe) 12 (sial) 8O2] (OH) 16 (chlorite) and so on.

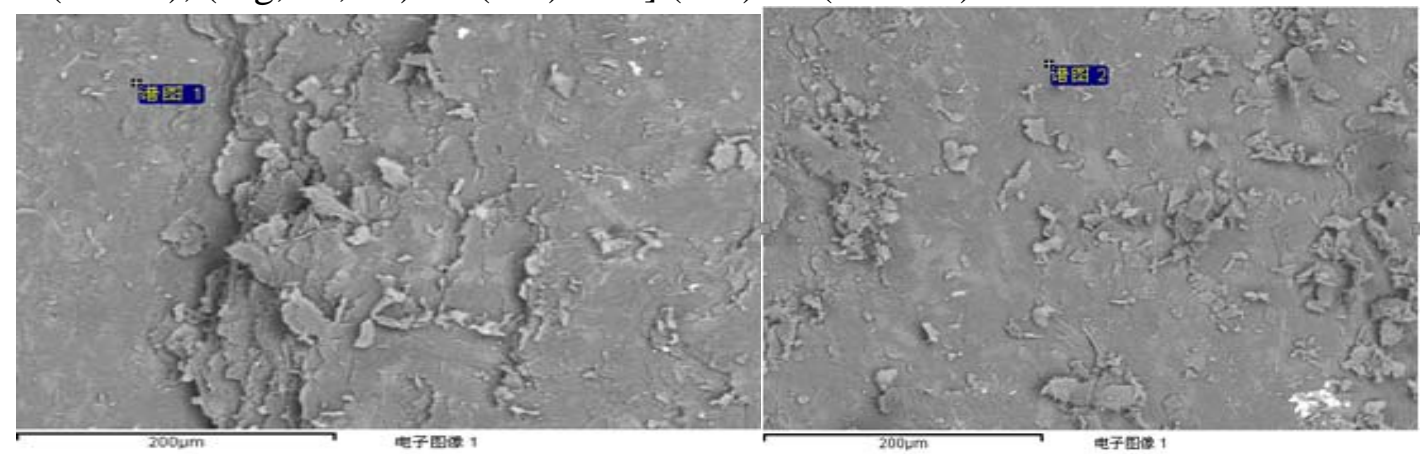

Fig. 1. $\mathrm{X}$ - ray diffraction experiment

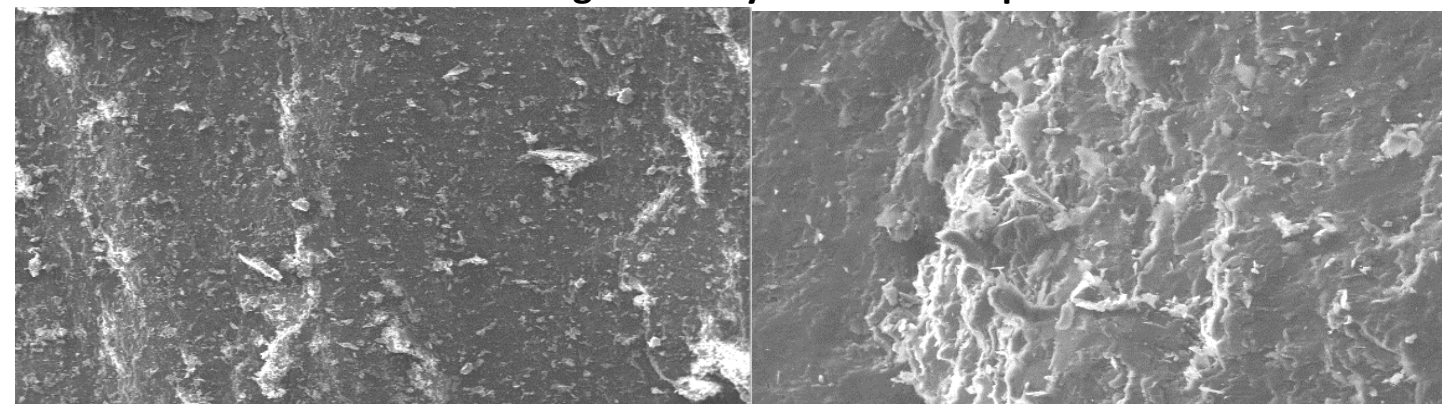

Fig 2.electron micrographs of phyllite disc

Phyllite grinding electron microscope test (Figure2) show that: phyllite rocks containing three quarters of sericite and crystallite biotite. The rest of the feldspar mineral. Sericite content more than $60 \%$, small, scaly, silver luster; sericite masterbatch sparse distribution of chlorite, disordered interspersed during a few irregular granular white fine quartz, and black fine grained magnetite.

\section{The mechanical properties of the original rock phyllite}

Rock can be divided into: hard stone, medium hard stone or soft stone. Hard stone materials can be directly used to fill embankment, and soft stone because of its poor strength, it can be broke in the embankment compaction process easily, poor water stability, with a softening, resulting in its strength will occur in the immersion state of decay, affect the stability of the roadbed. In accordance with the "standard methods for testing of engineering rock mass" （GB / ts0266-99 ) sampling of the scene of phyllite rock block cut into irregular small square divided into not saturated with water or water in the two groups, uniaxial compressive strength test results such as Table 1 shows.

Table 1 results of uniaxial compressive strength test

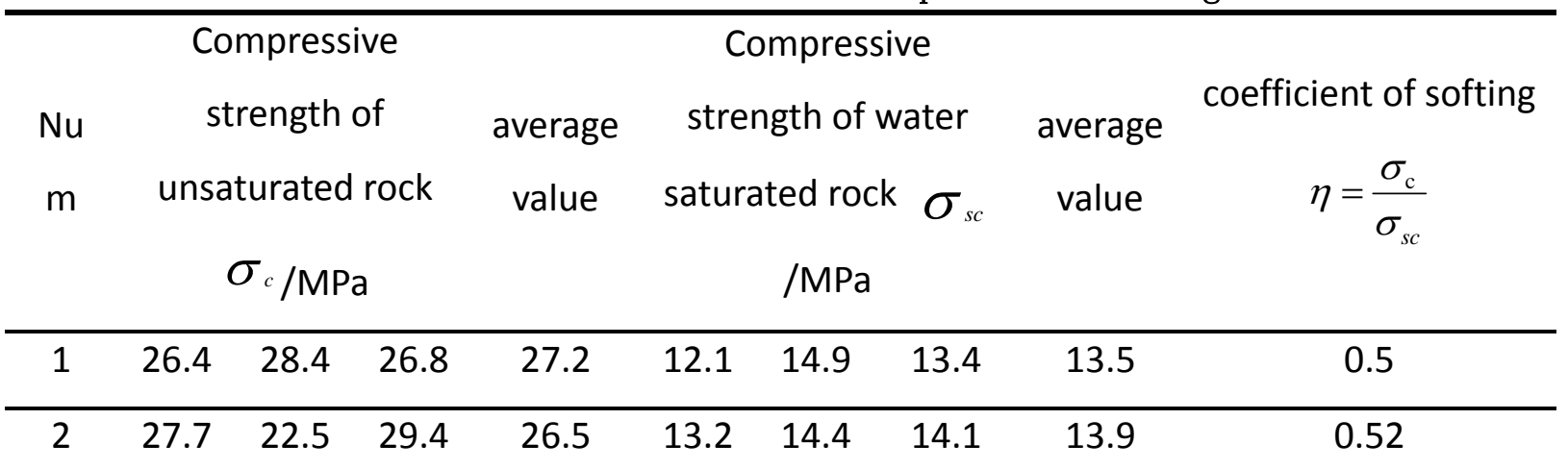

By uniaxial compressive strength test (Table 1) we can see the phyllite water saturated state will affect its compressive strength, after full of water the compressive strength attenuation to decrease to $50 \%$. The 0.52 largest phyllite softening coefficient is less than 0.75 , indicating that the phyllite with performance water softening, the water stability is bad. According to Table 2.1 data shows, the uniaxial compressive strength of raw rock phyllite measured values in the range of $12 \sim 30 \mathrm{MPa}$, according to the engineering rock mass test method standard " (GB/50218-94) can determine that 
the rock is a kind of soft rock, easily broken and water stability is poor, the roadbed filling materials, in groundwater and surface water intrusion and vehicle load repeatedly under the effect of prone to failure.

\section{Properties of weathered phyllite filler modified by cement}

According to previous research, 7 days of saturated unconfined compressive strength is the controlling factor of chemical modification to the strength of the soil, and when the field soil unconfined compressive strength is more than $0.5 \mathrm{MPa}$,it will be able to meet the subgrade filling requirements on water stability and dynamic stability requirements.

Through a combination of unconfined compressive strength test, and two factors analysis of variance method, we study thecement content, gradation, and their interaction on the cement modified phyllite stuffing without side limit compression strength value changes. With the requirements of the premise in the mechanical properties ismeted, selecting the most economical cement amount and the gradation composition and test it's water stability of cement modified phyllite stuffing. Relationship between unconfined compressive strength and cement content under different gradation.

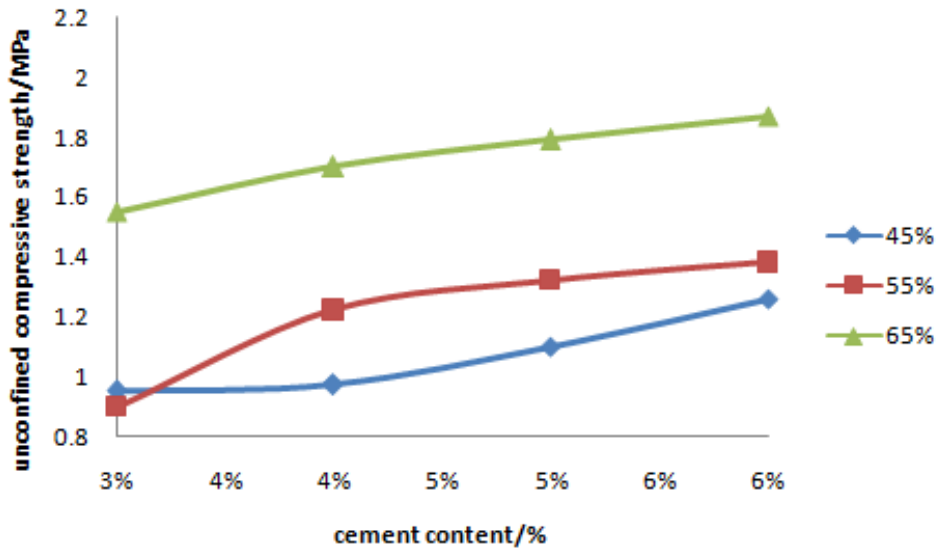

Fig. 3 Relationship between unconfined compressive strength and cement content

Unconfined compressive strength and cement content relationship (Figure 3) can be obtained, when the content of coarse aggregate is constant, cement content changes will affect the unconfined compressive strength values change, and values are positively related to relationship. With the increase of the cement content, strength of different coarse aggregate content grading phyllite stuffing also increased, which in coarse aggregate content for 55\% of the intensity increased maximum, which is due to the filler particles distributed evenly and cement reaction more fully in. $45 \%$ grain group strength low because of the coarse material content less cement and failed to fully formed by the reaction of the cement soil skeleton, and the intensity is obviously lower, so take the gradation of coarse aggregate content of $55 \%$ is the best. With the increase of the dosage of cement, it will not only increase the cost, but also cause the roadbed diseases. Can meet the requirements of water stability and dynamic stability can be seen from Figure 3, when 55\% of coarse aggregate content, cement content is $3 \%$ to $5 \%$ range, no side limit compressive strength values were more than $0.5 \mathrm{MPa}$, and than not soaked state value is attenuated by $6.5 \%$. So choosing coarse aggregate gradation and cement content of $55 \%$ to $3 \%$ can meet the design requirements, and is the most reasonable.

\section{Summary}

1) With phyllite rock, filler indoor mineral analysis test, mechanical properties test, immersion disintegration test analysis of its physical and mechanical properties. The results show that the main mineral composition of the rocks is sericite and crystallite biotite and feldspar minerals; its low 
strength belong to the category of soft rock; thousands of pieces of protolithes of filler poor water stability, after the case of water will be collapsed, crushing and pulverization; is a poor filler.

2) Through the cement modified phyllite stuffing without side of unconfined compression strength test analysis shows that no side limit the amount of compressive strength with cement, coarse aggregate content was positively related to relationship. The interaction of cement and coarse aggregate content can be increased without side limit compression strength. The cement content is $3 \%$, the content of coarse aggregate gradation is $55 \%$, and that meet the requirements of economy and the best combination of mechanical properties.

\section{Reference}

[1] Mao Xue Song, Zheng Xiaozhong, Ma Biao, et. Weathering phyllite filling subgrade humidification deformation field test analysis [J]. Rock and soil mechanics, 2011, 32 (8): 2300-2306.

[2] Zhou Leingang. Highway subgrade of strong weathering phyllite filling technology [D] Chang'an University, 2012

[3] Zheng Xiaozhong. Weathered phyllite subgrade wetting deformation characteristics of [D]. Chang'an University, 2012

[4] Huang Chengjia. Phyllite fillers gradation study influence the stability of roadbed [D]. Chang'an University, 2012

[5] Mao Xue Song, Meng Qingmeng, Fan Yushuo. Water for the weathered phyllite filling test tank subgrade resilient modulus [J]. Wuhan University of Technology: edition of transportation science and engineering, 2014, 38 (4): 767-770. 